\title{
ASPECTOS FORMAIS SOBRE O REGISTRO DE MEDICAMENTOS E OS LIMITES DA ATUAÇÃO JUDICIAL
}

\author{
FORMAL ASPECTS ON MEDICINE REGISTER AND
} THE LIMITS OF THE JUDICIAL PERFORMANCE

Marcelo Palis Horta ${ }^{(*)}$

\section{RESUMO}

Neste artigo, será possível compreender o que é o registro de medicamentos, com seu conceito, características e procedimentos, além de verificar as razões de tantas controvérsias judiciais referindo-se ao tema. Por óbvio, não há o desiderato de espancar todas as dúvidas existentes sobre o tema, nem produzir um manual completo sobre registro de medicamentos, mesmo porque $O$ assunto ainda está começando a se desenvolver. $O$ trabatho tem o escopo, sim, de iniciar a discussão sobre tema tão moderno e importante.

\section{Palavras-chave}

Registro de Medicamentos, Vigilância Sanitária, Saúde Pública, Mandado de Segurança, Administração Pública.

\section{ABSTRACT}

In this article, it will be possible to understand what it is medicine register, with its concept, characteristics and procedures, besides verifying the reasons of as many controversies judicial mentioning the subject to it. For obvious, it does not have the desideratum to spank all the existing doubts on the subject, nor to produce a complete manual on medicine register, exactly

(*) Graduando da Faculdade de Direito da Universidade de Brasília, Membro do Grupo de Estudos em Direito Sanitário e do Núcleo de Regulação Setorial da Faculdade de Direito da UnB. 
because the subject is still starting to develop. The work has the target, yes, to initiate the quarrel on so modern and important subject.

\section{Key-words}

Medicine Register, Sanitary Monitoring, Public Health, Mandamus, Public Administration.

\section{INTRODUÇÃO}

Este trabalho surgiu da verificação de diversos mandados de segurança impetrados em primeira instância com o intuito de ver registrados medicamentos cujos pedidos não foram analisados pelo órgão competente do Ministério da Saúde. O grande número dessas ações serviu de acicate para a produção deste artigo, cujo intuito é compreender o tema do registro de medicamentos, em especial quanto às exigências e requisitos técnicos e formais para sua concessão.

Inicialmente, buscou-se estudar esses processos, o que foi permitido pela participação num convênio estabelecido entre a Universidade de Brasília e a Agência Nacional de Vigilância Sanitária para compilar e analisar a jurisprudência existente sobre temas de vigilância sanitária.

Em seguida, passou-se à compilação de jurisprudência em segundo e terceiro graus. Verificou-se que, a despeito do grande número de mandados impetrados em primeira instância, a quantidade de processos em tribunais não é de grande monta.

O passo seguinte, a pesquisa bibliográfica, foi o mais árduo. $A$ incipiência do tema implica pequena quantidade de escritos sobre o assunto. Mesmo artigos sobre áreas de vigilância sanitária são difíceis de achar. Buscou-se, então, fazer uma análise permeada por conceitos de direito administrativo, o que foi grandemente facilitado pela quantidade de material existente. A análise de legislação também foi uma forma bastante confortável de se desviar das dificuldades decorrentes da ausência de material bibliográfico.

\section{Registro de medicamentos}

É uma garantia à saúde pública que a produção e fabricação de certos produtos seja submetida ao regime da legislação sanitária e ao poder de polícia sanitária. O Estado-administrador vale-se de licenças, autorizações, registros, para controlar os bens que possam interferir com a saúde, a exemplo de alimentos, equipamentos médicos e produtos sanitários. 
A fantástica evolução tecnológica na indústria farmacêutica deu prazo ao incremento dos sistemas de vigilância de medicamentos. Isto porque, a despeito de ter proporcionado inestimável auxílio ao controle de problemas de saúde, a tecnologia farmacêutica tornou-se também capaz de causar homéricos danos aos consumidores - vide o caso da talidomida(1). É nesse contexto de busca pela diminuição dos riscos advindos do uso imoderado desses produtos que se insere a figura do registro de medicamentos.

De acordo com o art. $4^{2}$ da Lei n. $5.991 / 73$ e com o art. $3^{\circ}$ do Decreto n. $79.094 / 77$, medicamento é o produto farmacêutico, tecnicamente obtido ou elaborado, com finalidade profilática, curativa, paliativa ou para fim de diagnóstico.

O ponto de contato entre as definições doutrinárias ou legais é considerar como medicamento aquele que possui ação farmacológica, ou seja, constituido por um ou mais fármacos.

O registro é um ato privativo do órgão competente do Ministério da Saúde ${ }^{(2)}$ destinado a comprovar o direito de fabricação de produto submetido ao regime de vigilância sanitária ${ }^{(3)}$.

Para a Lei n. 6.360/76, no art. $3^{\circ}$, registro é a

"inscrição, em livro próprio após o despacho concessivo do dirigente do órgão do Ministério da Saúde, sob número de ordem, dos produtos de que trata esta Lei, com a indicação do nome, fabricante, da procedência, finalidade e dos outros elementos que os caracterizem".

Com essas definições, de registro e de medicamento, pode-se confortavelmente conceituar o registro de medicamento como sendo 0 ato administrativo ampliativo, privativo do órgão competente do Ministério da Saúde, destinado a comprovar o direito de fabricação de determinado produto com ação farmacológica destinado a fim profilático, curativo, paliativo ou de diagnóstico, por meio da inscrição em livro próprio do produto, com as indicações que o caracterizem.

A finalidade principal do registro é garantir que sejam entregues à população medicamentos que contenham componentes eficazes e que aten-

(1) Na definiçăo de talidomida do Dorland's illustrated medical dictionary. "Used commonly in Europe as a sedative and hypnotic in the early 1960's, it was discovered to be the cause of serious congenital anomalies in the tetus, notably amelia and phocomelia, when taken by a woman during early pregnancy. Tradução livre do autor: "Comumente usado na Europa comı um sedativo ou hipnótico no inicio da década de 1960 . foi descoberto como sendo a causa de sérias anomalias congènitas em fetos, notadamente amelia e focomelia, quando tomada por uma mulher no inicio da gestação". FRIEL, John P. (org.). Dorland's illustrated medical dictionary. $25^{\circ}$ ed. Philadelphia: W. B. Saunders, 1974, p. 1593.

(2) Portaria n. 1.461/MS, de 2000.

(3) Art. $3^{\circ}$ do Decreto n. 79.094/77. 
dam à destinação terapêutica indicada. Outro objetivo importante é o poder que o Ministério da Saúde, através do órgão competente, tem para, conhecendo os diversos tipos de substâncias usadas no País, a qualquer momento, por motivos de risco potencial à saúde ou por não serem mais benéficas do ponto de vista clínico-terapêutico, identificar quem as utiliza, proibir o seu uso ou exigir que as fórmulas sejam modificadas.

$\mathrm{O}$ registro de medicamentos é um ato administrativo ampliativo. Esta é uma classificação quanto aos resultados sobre a esfera jurídica do administrado, ou seja, sobre a esfera do laboratório a quem se concede o registro. De acordo com Bandeira de Mello, atos ampliativos são "os que aumentam a esfera de ação jurídica do destinatário"(4).

Segundo o consagrado entendimento de Hely Lopes Meirelles, são requisitos do ato administrativo: competência, finalidade, forma, motivo e objeto.

"Entende-se por competência administrativa o poder atribuído ao agente da Administração para o desempenho específico de suas funções. "(5) No caso do registro de medicamentos, a competência hoje é da Câmara de Medicamentos, sendo que o exercício das competências da Secretaria Executiva deste órgão cabe à ANVISA. A Câmara de Medicamentos, por óbvio, é atrelada ao Ministério da Saúde ${ }^{(6)}$.

A finalidade é o objetivo de interesse público a atingir. Não se concebe ato administrativo sem fim público.

"Motivo ou causa é a situação de direito ou de fato que determina ou autoriza a realização do ato administrativo" (grifos do original)(7). No caso do registro de medicamentos, sendo um ato vinculado(8), o órgão competente deverá verificar a ocorrência de todas as exigências legais e, caso estas se encontrem presentes no pedido de registro, deverá concedê-lo (o registro). $\| l e s^{(9)}$ :

É interessante tomar a definição de objeto dada por Hely Lopes Meire-

(4) MELLO, Celso Antônio Bandeira de. Elementos de Direito Administrativo. $3^{\circ}$ ed. São Paulo: Revista dos Tribunais, 1980 , p. 58.

(5) MEIRELLES, Hely Lopes. Direito Administrativo brasileiro. $26^{\circ}$ ed. atual. São Paulo: Malheiros, 2001, p. 143.

(6) Portaria n. 1.461/MS, de 2000.

(7) MEIRELLES, Hely Lopes. Direito Administrativo brasileiro. 26' ed. atual. Sảo Paulo: Malheiros, 2001, p. 145.

(8) Ato vinculado, para Diogenes Gasparini, é o praticado pela Administração Pública sem a menor margem de liberdade. A lei prescreve detalhadamente quando e como a Administração deve agir. GASPARINI, Diogenes. Direito Administrativo. $5^{*} \mathrm{ed}$. rev., atual. e aum. Sāo Paulo: Saraiva, 2000, p. 72.

(9) MEIRELLES, Hely Lopes. Direito Administrativo brasileiro. 26* ed. atual. São Paulo: Malheiros, 2001, p. 146. 
"Todo o ato administrativo tem por objeto a criação, modificação, ou comprovação de situações jurídicas concernentes a pessoas, coisas ou atividades sujeitas à ação do Poder Público. Nesse sentido, o objeto identifica-se com o conteúdo do ato, através do qual a Administração manifesta seu poder e sua vontade, ou atesta simplesmente situações preexistentes."

Inexiste dúvida quanto a dizer que a concessão do registro é o objeto do ato administrativo "registro de medicamento".

O último requisito é a forma. É um erro muito comum confundir a forma do ato com o procedimento administrativo. A forma é o revestimento material do ato, enquanto o procedimento é o conjunto de operações exigidas para sua perfeição. O procedimento administrativo, e não a forma do ato "registro de medicamento", constitui parte significativa do objeto principal deste artigo, não se devendo deixar enganar pela expressão "aspectos formais" que a intitula.

Para o registro de medicamentos, a forma exigida é a escrita, que deve ser publicada no Diário Oficial da União, quando então passará a produzir efeitos. Do documento de registro devem constar elementos tais como fórmula de composição, forma de apresentação, unidades farmacotécnicas, finalidade, entre outros.

\section{Procedimento para registro}

Uma série de requisitos e formalidades deve ser preenchida para que - Poder Público possa conceder o registro de determinado medicamento.

Inicialmente, percebe-se que o registro de medicamentos é inerente à empresa e seus estabelecimentos, previamente autorizados e licenciados. Dispõe o art. 17:

"Art. 17 - O registro dos produtos submetidos ao sistema de vigilância sanitária fica sujeito à observância dos seguintes requisitos:

(omissis)

IV - Comprovação de que a empresa se acha autorizada a funcionar no Pais, na forma do artigo $50^{(10)}$ da Lei $n$. 6.360, de 23 de setembro de 1976 e deste Regulamento.

(10) "Art. 50. O funcionamento das empresas de que trata esta Lei dependerá de autorização do Ministério da Saúde, à vista da indicaçăo da atividade industrial respectiva, da natureza e espécie dos produtos e da comprovaçāo da capacidade técnica, cientifica e operacional, e de outras exigências dispostas em regulamentos $\theta$ atos administrativos pelo mesmo Ministério.

Parágrafo único. A autorização de que trata este artigo será valida para todo o território nacional e deverá ser renovada sempre que ocorrer alteração ou inclusão de atividade ou mudança do sócio ou diretor que tenha a seu cargo a representaçăo legal da empresa." 
V - Comprovação de que o estabelecimento de produção acha-se devidamente licenciado pelo órgão de vigilância sanitária competente dos Estados, do Distrito Federal ou dos Territórios.

$\mathrm{VI}$ - Comprovação de que o estabelecimento de fabricação tem assistência de técnico responsável, legalmente habilitado para aquele fim.

(omissis)

VIII - Comprovação da existência de instalações e aparelhagem técnica de equipamentos necessários à linha de industrialização pretendida."

Vê-se, destarte, que os primeiros requisitos para o registro referem-se à empresa e às facilidades de seus estabelecimentos.

\subsection{Decreto n. $79.094 / 77$}

Os dois principais instrumentos legais referentes ao registro de medicamentos são a Lei n. 6.360/76 e o Decreto que a regulamenta, de n. 79.094/ 77. Como as disposições da Lei n. 6.360/76 são reproduzidas e/ou desenvolvidas no Decreto, analisar-se-á apenas este.

Além dos requisitos referentes à empresa, já detalhados no inicio deste capítulo, é necessário analisar os demais dispositivos atinentes à matéria em estudo.

O Título II (Do Registro) é iniciado com o dizer do art. 14 de que nenhum dos produtos submetidos ao regime de vigilância sanitária de que trata o Decreto poderá ser industrializado, vendido ou consumido antes de registrado no órgão competente do Ministério da Saúde.

O parágrafo terceiro do supracitado artigo faz menção ao prazo legal de que dispõe o órgão competente para se manifestar sobre o registro do medicamento, concedendo-o ou não. Esse prazo, de 90 dias, será alvo de consideração mais aprofundada no próximo capítulo.

O nono parágrafo trata de exigências formais a constarem do registro. Dispõe, in verbis:

"§ $9^{9}$ - Constará obrigatoriamente do registro de que trata este artigo a fórmula de composição do produto, com a indicação das substâncias utilizadas, suas dosagens, as respectivas formas de apresentação e o número de unidades farmacotécnicas."

O parágrafo seguinte trata de competência. Afirma que a concessão de registro é de atribuição privativa do Diretor do órgão de vigilância sanitá- 
ria competente do Ministério da Saúde. A letra do artigo impõe considerar que competente para conceder registro de medicamento é o Diretor da Secretaria Executiva da Câmara de Medicamentos.

O art. 17, em seu inciso I, dispõe que é necessário que o produto seja designado por nome que o distinga dos demais do mesmo fabricante e dos da mesma espécie de outros fabricantes.

$O$ inciso terceiro propõe uma pletora de elementos obrigatórios a constarem do relatório elaborado pelo responsável técnico do estabelecimento requerente. Menciona:

"a) fórmula ou fórmulas de composição correspondendo às formas de apresentação do produto com a especificação das quantidades das substâncias expressas de acordo com o sistema métrico decimal;

b) relação completa do nome, sinônimos e quantidades de cada substância, ativa ou não, que figure em cada unidade de dose;

c) indicação, finalidade ou uso a que se destine;

d) modo e quantidade a serem usadas, quando for o caso, restrições ou advertências;

e) descrição da técnica de controle da matéria-prima e do produto acabado, com as provas de sua execução;

f) contra-indicações, efeitos colaterais, quando for o caso;

g) as diversas formas de apresentação;

h) os demais elementos necessários, pertinentes ao produto de que se trata, inclusive os de causa e efeito, a fim de possibilitar a apresentação pela autoridade sanitária."

Diversas outras exigências estão presentes no formulário de petição, a ser analisado no próximo item.

O inciso VII faz mais algumas exigências técnicas ao fabricante, determinando a apresentação de modelos de rótulos, desenhados e com a indicação das dimensões a serem utilizadas, e das bulas e embalagens, quando for 0 caso.

O Título III (Do Registro dos Medicamentos, Drogas e Insumos Farmacêuticos) determina outra lista de requisitos específicos para o registro, no art. 18. São eles:

"I - Que o produto, através de comprovação científica e de análise, seja reconhecido como seguro e eficaz para o uso a que se propõe, e 
possua a identidade, atividade, qualidade, pureza e inocuidade necessárias.

11 - Tratando-se de produto novo, que sejam apresentadas amplas informações sobre a sua composição e o seu uso, para avaliação de sua natureza e determinação do grau de segurança e eficácia necessários.

III - Apresentação, quando solicitado, de amostras para análises e experiências que sejam consideradas necessárias pelos órgãos competentes do Ministério da Saúde.

IV - Quando houver o emprego de substância nova na composição do medicamento, entrega de amostra respectiva, acompanhada dos dados químicos e físico-químicos ou biológicos que a identifiquem.

$\mathrm{V}$ - Na hipótese referida no item IV, quando os métodos indicados exigirem padrões, reagentes especiais, meios de cultura, cepas microbiológicas, e outros materiais específicos, a empresa ficará obrigada a fornecê-los ao laboratório oficial de controle competente se julgado necessário.

VI - Quando se trate de droga ou medicamento cuja elaboração necessite de aparelhagem técnica específica, prova de que o estabelecimento se acha devidamente equipado e mantém pessoal habilitado ao seu manuseio ou tem contrato com terceiros para essa finalidade."

Os arts. 19 e 20 tratam da avaliação técnica do órgão competente do Ministério da Saúde. Dispõem:

"Art. 19 - Para a concessão do registro de drogas, medicamentos e insumos farmacêuticos, as informações contidas nos respectivos relatórios deverão ser reconhecidas como cientificamente válidas pelo órgão competente do Ministério da Saúde.

Art. 20 - As informações descritivas de drogas ou medicamentos serão avaliadas pelo órgão ou pela entidade competente do Ministério da Saúde ou analisadas pelo seu competente laboratório de controle, em cujas conclusões deverá basear-se a autoridade sanitária para conceder ou denegar o registro."

\subsection{Preenchimento dos formulários de petição}

São duas as petições necessárias para compor o pedido de registro de medicamentos. São denominadas simplificadamente FP1 e FP2. Tais documentos devem ser preenchidos à máquina ou com letra de fôrma legi- 
vel, não podendo conter rasuras. Devem ser preenchidos em duas vias, sendo que uma delas é devolvida ao requerente como recibo, após a protocolização.

Os campos de preenchimento dos formulários são em geral quadriculados. Cada quadrícula deve conter apenas um caractere alfanumérico. Em se tratando de campo numérico, deve-se iniciar o preenchimento da direita para a esquerda. Sendo campo alfabético, inicia-se pela primeira quadrícula à esquerda, deixando sempre um espaço em branco entre as palavras ou expressões. Não se deve utilizar hífen para separar palavras em caso de duas linhas de preenchimento. Basta continuar o vocábulo como se a linha fosse contínua. Quando o campo for insuficiente para a informação, deve-se manter as palavras-chave e abreviar as demais, sem prejuizo do entendimento. Não são aceitas folhas em anexo para complementação de dados.

A formação do processo demanda nove documentos: petições FP1 e FP2 devidamente preenchidas, em duas vias (original e cópia); comprovante de pagamento de preço público em duas vias (original e cópia, devidamente autenticadas e/ou carimbadas); cópia da publicação da Autorização de Funcionamento da Empresa; comprovante do registro de produto acompanhado das respectivas bulas originais, aprovadas no pais de origem e em outros, se houver; Relatório de Experimentação Terapêutica, elaborado e apresentado de acordo com a seqüência disposta na Resolução $n$. 01/88, de 5.1.89, do Conselho Nacional de Saúde, enfatizando a biodisponibilidade e toxicidade; relatório técnico do produto(11); modelos de rótulos, bulas e em-

(11) Contendo os seguintes itens:

- Dados Gerais:

a) Forma farmacèutica de apresentação;

b) Fórmula de composiçâo, indicando os componentes básicos por dose a ministrar ou, se possivel, por grama, mililitro, unidade padrāo internacional:

c) vias de administração e/ou modo de usar;

d) indicações principais, finalidade ou uso a que se destine;

e) indicaçōes terapẻuticas complementares:

f) contra-indicaçōes, efeitos colaterais, reaçōes adversas;

g) restriçōes ou cuidados que devem ser considerados:

h) prazo de validade:

i) cuidados de conservação;

j) instruções de uso, quando for o caso.

- Farmacodinámica:

a) modo de açào;

b) posologia (doses máximas e minimas):

c) justificativas das doses indicadas.

- Produção e Controle de Qualidade:

a) a fórmula completa da preparação, com todos os seus componentes especificados pelos nomes técnicos. correspondentes e sinónimos de acordo com a Denominaçāo Comum Brasileira - DCB, as quantidades de cada substáncia expressa no sistema métrico decimal ou em unidade padrão, consignando as substâncias utilizadas como veiculo ou excipiente:

b) o processo de fabricação, com a descriçảo concisa das operaçōes a serem realizadas: 
balagens, datilografados em duas vias; cópia do Alvará de Licenciamento da Empresa e/ou Alvará Sanitário; e comprovante de que o estabelecimento de fabricação tem assistência do técnico responsável, habilitado para aquele fim.

Os campos a serem preenchidos nos formulários FP1 e FP2 tratam de aspectos técnicos do produto e dados da empresa. Informações tais como classe terapêutica, princípio ativo, fórmula, forma física, concentração, quantidade, volume e unidade farmacotécnica devem ser discriminadas nesses campos.

\section{Controvérsias judiciais}

Num convênio que vem sendo realizado entre ANVISA e UnB, com o intuito de organizar a jurisprudência atinente a matérias de vigilância sanitária, verificou-se que uma significativa porcentagem de açōes ajuizadas em tribunais de primeira instância versa sobre o registro de medicamentos.

Esses casos, de modo geral, são mandados de segurança que têm por impetrante algum laboratório e é apontado como autoridade coatora o Secretário de Vigilância Sanitária do Ministério da Saúde. Note-se que os processos analisados foram impetrados anteriormente à criação da ANVISA, razão por que consta como réu não o Diretor da Secretaria Executiva da Câmara de Medicamentos, e sim a autoridade que cumpria a mesma função antigamente.

c) relatório descritivo de controle de qualidade, realizado com os componentes ativos de fórmula do produto, bem como os testes de estabilidade e físico-químicos da matéria-prima e do produto acabado;

d) os limites de tolerância para os ensaios e para os desvios de dosagem, na ausência de normas oficiais:

e) o código ou convenção utilizada pela empresa para identificação dos lotes ou partidas do produto;

f) relatório contendo as indicaçōes técnicas de que não há incompatibilidade física ou quimica entre a embalagem a ser adotada e os componentes da fórmula do produto;

g) cuidados de armazenagem e transporte.

- Dados Complementares:

a) citar a inscrição da subståncia ou componentes básicos da fórmula em farmacopéia, formulários ou publicações oficiais de padronização farmacêutica e/ou de conceituação cientifica;

b) anexar a bibliografia sobre o produto e a literatura pertinente, acompanhada, quando de origem estrangeira, de tradução integral do trabalho original in vernaculo. O Departamento Técnico poderá solicitar trabalhos que venha a considerar necessários à avaliação da documentação científica, com duplicata para seu arquivo;

c) havendo a inclusão de substáncias entorpecentes, hipnótica ou barbitúrica, demonstrar obediência às disposiçỏes especiais a que estão submetidas;

d) apresentar as vantagens da fórmula proposta, com justificativa sob o ponto de vista clínico;

e) outros elementos que sejam próprios ou necessários, inclusive os destinados a ajuizar causa $\theta$ efeitos, de modo a facilitar conclusões corretas por parte das autoridades sanitárias. 
As razões dos impetrantes não variam muito. De forma geral, requerem ao Judiciário que registre o medicamento que produzem, alegando que o órgão responsável pelo registro deixou de se manifestar no prazo legal.

As decisões, também quase de maneira univoca, dão-se no sentido de denegar a segurança, sob o fundamento de que o Poder Judiciário não pode substituir a autoridade competente para o registro. É verdade que um ou outro juiz concede a segurança, mas são situações claramente aberrantes que não se sustentam em segunda instância.

A despeito da correção das decisões, o objetivo deste capítulo é compreender a atitude do órgão competente para o registro de medicamentos, sob o ponto de vista legal e principiológico.

\subsection{Princípios da Administração Pública}

O Direito Administrativo está informado por determinados principios, alguns deles próprios também de outros ramos do Direito Público e outros deles específicos e enquadrados como setoriais, do Direito Administrativo. Deve-se analisar, com referência ao registro de medicamentos, os princípios da legalidade, supremacia do interesse público e eficiência.

É inegável que a vontade da Administração Pública é a que decorre da lei. A lei define a atuação administrativa e estabelece seus limites. Segundo o princípio da legalidade, a Administração Pública só pode fazer o que a lei permite.

Conforme demonstrado anteriormente, o registro de medicamento é um ato vinculado. Portanto, ocorrendo os requisitos definidos legalmente para sua concessão, esta deve ocorrer. O administrador deverá, portanto, verificar o adimplemento de tais exigências no prazo definido em lei. É aí que reside o fundamento da impetração dos referidos mandados de segurança.

Comanda 0 art. $12, \S 3^{\circ}$, da Lei n. 6.360/76:

"O registro será concedido no prazo máximo de 90 (noventa) dias, a contar da data de entrega do requerimento, salvo nos casos de inobservância desta Lei ou de seus regulamentos."

No mesmo sentido, o Decreto n. 79.094/77:

"Art. 14 - omissis

$\S 3^{\circ}-O$ registro será concedido no prazo máximo de 90 (noventa) dias, a contar da data da entrega do requerimento, salvo nos casos de inobservância da Lei n. 6.360, de 23 de setembro de 1976, deste Regulamento ou de outras normas pertinentes." 
Portanto, a única margem de liberdade que tem a Administração é se manifestar durante qualquer dia dentre esses noventa permitidos.

O princípio da supremacia do interesse público, também chamado de princípio da finalidade pública, indica que as normas de direito, embora protejam reflexamente o interesse individual, têm por objetivo precipuo atender ao interesse público, ao bem-estar coletivo. É um princípio que regula todo o Direito Público e vincula a Administração em todas as suas decisões.

Tornou-se comum entre os profissionais do Direito o discurso legalista que entende que a atuação da autoridade sanitária só será admitida se em conformidade com a lei, por mais convincente que seja o argumento da supremacia do interesse público quando se trata de preservar a saúde. Chegam ao absurdo de afirmar que o registro de medicamentos deve de fato ser concedido judicialmente no caso de o órgão competente não se manifestar no prazo definido por lei. Deve-se levar em conta que o registro de medicamento afeta a saúde pública de maneira intensa e, por vezes, indelével. Um medicamento prejudicial à saúde que conseguir o registro por causa da delonga da autoridade sanitária pode causar males indescritiveis à população, dependendo da extensão do uso. Por tais razões, por mais que se deva reprovar a conduta morosa do ente sanitário, não se pode fazer substituir o Judiciário à autoridade competente. A supremacia do interesse público, nesse caso, não permite que outra solução seja dada, por mais ilegal que seja a atitude do órgão competente para registro.

O princípio da eficiência impõe a todo agente público realizar suas atribuições com presteza, perfeição e rendimento funcional.

O órgão competente para o registro de medicamentos, ao prestar informações nos mandados de segurança, vem afirmando que o prazo definido legalmente é exiguo, dada a enorme quantidade de pedidos formulados e o pequeno número de funcionários para avaliá-los.

Um aspecto importante deve aqui ser considerado. A autoridade apontada como coatora passou a alegar que, por razão de portaria ministerial, passaram a eleger prioridades na verificação dos pedidos. São avaliados prioritariamente, na ordem: medicamentos constantes da Relação Nacional de Medicamentos Essenciais; medicamentos utilizados em campanha de saúde pública; medicamento sem similar terapêutico no mercado nacional; medicamentos novos a serem utilizados em patologias a exemplo da AIDS; e medicamentos utilizados em doenças crônico-degenerativas.

A despeito da gritante arbitrariedade da ordem dessa lista, o que mais claramente repugna ao Direito é que a portaria que a definiu( ${ }^{(12)}$ arrogou-se 
um campo de atuação que a Lei não the deu. Em momento algum a Lei $n$. 6.360/76 ou o Decreto $n$. 79.094/77 definiu qualquer ordem de prioridade para a avaliação de registros ou mesmo permitiu que alguma Portaria o fizesse.

Nada obstante, não se pode deixar de levar em conta a alegação de impossibilidade de avaliar todos os pedidos formulados. Ora, sabe-se que a Lei que definiu o prazo de noventa dias foi feita em época em que a quantidade de pedidos era incontestavelmente inferior ao que existe hoje. A evolução tecnológica dos laboratórios nacionais e a abertura crescente aos produtos estrangeiros determinam a adequação da legislação a essa nova realidade. Para que não se esgote a capacidade do órgão competente, ainda é preciso que se amplie o quadro de funcionários. Esse dever ser, entretanto, não altera nada quanto à ilegalidade do procedimento da autoridade competente. Se não há manifestação no prazo definido, há ilegalidade, mesmo sendo impossivel haver decisão sobre todos os pedidos.

Tal ilegalidade, entretanto, não possibilita que o Juiz substitua a autoridade competente, mesmo porque ele não tem capacidade técnica para avaliar o pedido de registro com o rigor exigido pela lei.

\section{Análise de jurisprudência}

\subsection{Remessa Ex Officio em Mandado de Segurança n. 96.01.18079-6/DF}

Trata-se de remessa oficial para apreciação da decisão do Juízo Federal da 6 Vara do Distrito Federal, que concedeu a segurança impetrada, no sentido de determinar às autoridades coatoras (Diretor do Departamento Técnico-normativo e Chefe da Divisão de Produtos da Secretaria Nacional de Vigilância Sanitária do Ministério da Saúde) que apreciem e decidam quanto ao registro do produto Amicacina, no prazo de cinco dias a contar da intimação do julgado.

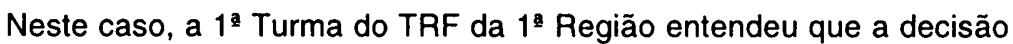
em primeira instância, no sentido de conceder parcialmente a segurança, foi prudente, negando provimento à remessa oficial.

Muito embora haja manifestações no corpo deste trabalho no sentido de entender que a segurança deva ser denegada nesses casos, a decisão do tribunal afigura-se correta. Deve-se compreender que o juiz federal não determinou o registro do medicamento, o que seria uma clara substituição ao órgão competente. $O$ que fez foi determinar que esse órgão saísse da posição de inércia e se manifestasse sobre o pedido, o que deveria ter feito no prazo legal. A decisão, portanto, combateu a ilegalidade da administração 
sem substituir-se a ela, administração, o que configuraria uma outra atitude ilegal, porque violadora do preceito constitucional de separação dos Poderes.

\subsection{Remessa Ex Officio em Mandado de Segurança n. 96.01.28386-2/DF}

Trata-se de remessa oficial para apreciação da decisão de primeira instância que concedeu a segurança no sentido de que a autoridade coatora apreciasse os pedidos de registro formulados pela autora

Mais uma vez resta, à primeira vista, a impressão de que o juízo de primeiro grau errou ao conceder a segurança. Entretanto, a decisão é de ser aplaudida, porque remediou a situação de ilegalidade do órgão competente sem substituir sua capacidade.

O que se deve ressaltar, nesse caso, é o pedido formulado pelo autor, diferente da maioria dos pedidos formulados com base em registro de medicamentos. Enquanto o "pedido-médio" formulado é no sentido de requerer do Judiciário o registro do produto, aqui se viu um pedido no sentido de requerer a manifestação do órgão competente sobre o pedido de registro. Nem haveria como denegar a segurança, uma vez que o prazo para manifestação, de noventa dias, já havia se esgotado, quedando a manifestação da autoridade coatora como obrigatória.

\subsection{Apelação Cível n. 96.01.45348-2/DF}

Trata-se de apelação interposta contra sentença prolatada em primeira instância que julgou improcedente a pretensão da parte autora de ver a União condenada a efetuar o imediato registro dos medicamentos apresentados perante a Secretaria de Vigilância Sanitária do Ministério da Saúde.

Esse caso, pela abrangência dos votos (tanto o vitorioso quanto o vencido), é de grande interesse.

A juiza relatora, em seu voto, expõe a dicotomia existente entre legalidade e supremacia do interesse público no que tange ao registro de medicamentos. Defendendo tese bem construída e moderna, diz:

"É fato que a Lei n. 6.360/76 estipula o prazo de noventa dias para que a Administração conceda o registro do medicamento, com vistas a sua fabricação e futura colocação no mercado de consumo. Mas esta mesma lei tem limites à sua ef.cácia que se convertem em verdadeiras barreiras intransponiveis, pelo mero decurso do exíguo lapso temporal de 90 (noventa) dias. 
O limite material é o interesse público, a saúde coletiva.

O limite formal é a Constituição Federal, supedâneo de todo o ordenamento jurídico, que, embora tenha recepcionado a Lei n. 6.360/76, conferindo-Ihe existência e obrigatoriedade, decerto não o fez violando os seus próprios princípios e postulados, dentre os quais se sobressaem: a inviolabilidade do direito à vida (art. 5ㅜ, capuf); a função social da propriedade (art. 5, XXIII); o direito à saúde (art. 6), bem como os arts. 197 e $200, \mid$ (...)"

E de fato a saúde pública, representando o interesse coletivo, é de ser posta em primeiro lugar, à frente da ilegalidade da não-manifestação, que por si só não possibilita o imediato registro do medicamento.

A tese do voto vencido tampouco merece censura. Veja que não foi vencido por conceder a segurança para determinar o registro do medicamento, e sim para determinar a manifestação do órgão competente. Menciona, também, o juiz o fato de que o remédio para a exigüidade do prazo legal de noventa dias é a reforma da Lei pelo legislador. Afirma que essa razão não pode ser alegada pela autoridade coatora para deixar de se manifestar prontamente sobre o registro.

\subsection{Mandado de Segurança n. 3.202-0/DF}

Trata-se de mandado de segurança impetrado contra ato do Ministro da Saúde e do Diretor da Secretaria de Vigilância Sanitária, que suspendeu até segunda ordem a liberação de registro de todos os produtos de competência liberatória da Secretaria de Vigilância Sanitária.

A decisão, correta e normal, foi no sentido de não conceder o registro pedido pelo impetrante. Em parágrafo digno de nota do voto do relator, diz-se:

"O pedido, no caso, foi expresso, para que se determinasse o imediato registro dos produtos, impossivel de ser atendido, sem a indispensável análise técnica, até porque sujeitaria o público, o consumidor, a eventuais riscos à sua saúde."

Vê-se que o STJ, no caso, no mesmo viés que o restante do Poder Judiciário, não se arroga o direito de substituir a autoridade competente para 0 registro de medicamentos.

Ademais, nota-se indisputável apego à supremacia do interesse público, prezando a saúde coletiva em face dos interesses do laboratório.

\section{CONCLUSÃO}

A exposição feita até aqui permite tecer, à guisa de conclusão, algumas considerações. Foi possível definir registro de medicamento como sen- 
do o ato administrativo ampliativo, privativo do órgão competente do Ministério da Saúde, destinado a comprovar o direito de fabricação de determinado produto com ação farmacológica destinado a fim profilático, curativo, paliativo ou de diagnóstico, pela inscrição em livro próprio do produto, com as indicações que o caracterizem.

Buscou-se explanar com exatidão todo o procedimento administrativo necessário à concessão do registro de medicamentos, através da exposição da legislação atinente ao tema e das instruções de preenchimento dos formulários de petição de registro. Tal atitude foi tomada para que se pudesse analisar com maior base os casos judiciais que vêm se formando em torno do tema do registro, em decorrência da morosidade da manifestação do Poder Público quanto aos pedidos feitos pelos laboratórios.

Nesse aspecto, verificou-se que o Poder Judiciário, ao analisar os casos, não poderia, sob pena de incorrer em inconstitucionalidade, substituirse ao administrador para conceder o registro, uma vez que um juiz não possui a qualificaçăo técnica para verificar a qualidade de medicamentos.

Entendeu-se, ainda, que ao principio da supremacia do interesse público, num caso tal, que tanto afeta a saúde pública, deve ser dada preferência em face dos principios da legalidade e eficiência, que, apenas por não terem sido cumpridos, não podem determinar o imediato registro de medicamento por parte da autoridade judicial. Isto é, a atitude ilegal do administrador ao não se manifestar no prazo legal sobre o registro de medicamento não implica o automático registro.

Por fim, analisaram-se decisões de tribunais, para chegar à conclusão de que o Poder Judiciário, uniformemente, vem defendendo a supremacia do interesse coletivo ao não deferir os pedidos de registro feitos pelos laboratórios por razão da inércia dos órgãos competentes, conforme as razões expostas neste artigo.

\section{BIBLIOGRAFIA}

BPR - Consultoria, Projetos e Comércio Ltda. Guia de remédios. $4^{\text {a }}$ ed. atual. São Paulo: Escala Ltda., 1999.

CIRNE LIMA, Rui. Principios de Direito Administrativo. Porto Alegre: [s.e.], 1954.

DIAS, Hélio Pereira. Curso de extensão em Direito Sanitário. Brasilia: [s.e.], 2001.

. Direito de Saúde. $2^{\mathrm{a}}$ ed. Rio de Janeiro: Seção de Artes Gráficas da FSESP, 1979. 
DI PIETRO, Maria Sylvia Zanella. Direito Administrativo. $12^{\mathrm{a}}$ ed. São Paulo: Atlas, 2000;

FRIEL, John P. (org.). Dorland's illustrated medical dictionary. 25ª ed. Philadelphia: W. B. Saunders Company, 1974.

GASPARINI, Diogenes. Direito Administrativo. $5^{\mathrm{a}} \mathrm{ed}$ rev., atual. e aum. São Paılo: Saraiva, 2000.

GRECA, Alcides. Polícia sanitária. RDA 3/454.

MEIRELLES, Hely Lopes. Direito Administrativo brasileiro. $26^{\mathrm{a}}$ ed. atual. São Paulo: Malheiros, 2001.

MELLO, Celso Antônio Bandeira de. Elementos de Direito Administrativo. $3^{\text {a }}$ ed. São Paulo: Revista dos Tribunais, 1980. 